\title{
The Stigma of Failure in Organizations ${ }^{1}$
}

\author{
Geraldo Ferrer \\ Naval Postgraduate School \\ gferrer@nps.edu \\ Nicholas Dew \\ Graduate School of Business and Public Policy - Naval Postgraduate School \\ ndew@nps.edu
}

\begin{abstract}
Organizations with exceptional operational performance have generally achieved this status through management's diligence encouraging the workforce to innovate. The use of suggestion boxes to collect process improvement suggestions from the workforce is one such example, but they are not always successful. Some organizations do a good job collecting great ideas from their workers, both staff and managers, while others see little result from their efforts. This paper presents a formal model of the (dis)incentives for entrepreneurial behavior in organizations. The model extends research on the stigma of failure into organizations by examining the implications of more conservative and more experimental organizational cultures on the incentives for entrepreneurial action by the corporate-funded employee. The models explain how a forgiving organization that is willing to accept failure as well as success will lead to more product and process innovation. Contrariwise, it explains how a bureaucratic organization will rarely innovate because of its low tolerance for unsuccessful ventures.
\end{abstract}

Keywords: Corporate entrepreneurship, process improvement, conceptual model

\section{INTRODUCTION}

SCM almost invariably involves the pursuit of efficiency; it is the objective function of the operations manager par excellence. Yet because of the focus on efficiency the processes by which new efficiencies are designed, experimented, revealed and put into place can easily get lost. Consider Wal-Mart. Thanks to its well-designed distribution apparatus, its performance is perhaps without peer. Its low cost supply chain enables it to profitably sell more goods and services than any other company on the planet. And yet, by focusing on Wal-Mart's efficiency at profitably getting product into the hands of customers, the casual observer may miss the processes involved in exploring new ideas to become more efficient. According to one close observer of the firm, it is "easy to overlook the experiments. Wal-Mart has never been afraid to step gingerly into a business, or a way of doing busi- ness, stumble around, figure it out, and then take it chain wide." (Fishman, 2006 p. 36). Consider General Electric. Its successful deployment of Six-Sigma is the process improvement benchmark for any organization engaged in total quality management. Wal-Mart, General Electric and Monsanto belong to a set of notable corporations that have gone great lengths to develop an entrepreneurial culture that supports their continuous improvement and innovation efforts. By focusing on efficiency, we are at peril of ignoring the fundamental processes of SCM experimentation, dotted with successes and failures. The experimentation process needs to be better understood.

In this paper we take up this challenge. Based on a seminal study by Landier (2005), who examines why countries and regions differ in their cultural acceptance of entrepreneurial failure, we explore the entrepreneurial aspect of process improvement. In some countries and

1 We are greatly thankful to the Office of the Secretary of the United States Dept of Defense for providing the necessary funds for this research. We are also thankful to Retired Rear Admiral Jim Greene, the Naval Postgraduate School Acquisition Research Chair, Prof. Keith Snider, director of the Acquisitions Research Program, and to John Dillard, Brad Naegle and Rene Rendon for their insights into the dynamics of the US Dept of Defense major acquisition programs. 
regions, entrepreneurial failure is stigmatized; yet, in others, little social negativity is attached to failure. The term "stigma" refers to an attribute that is deeply discrediting that reduces "a whole and usual person to a tainted, discounted one" (Goffman, 1963, p. 3; Sutton \& Callahan, 1987, p. 406). For example, while failed entrepreneurs are often stigmatized in France and Japan, a culture exists in California's Silicon Valley in which failure is practically a badge of honor (Bengtsson, 2005; Saxonian, 1994).

Landier captured this basic phenomenon in a model of asymmetric information. In his study he explains that, when choosing potential projects, entrepreneurs in conservative cultures will pursue suboptimal, but safe, projects. If, in turn, they fail in these pursuits, this will indeed indicate that they are most likely unable to carry entrepreneurial activities to fruition. This information is circulated via a stigma of failure, which may be understood as a social mechanism for conveying information about the quality of individuals. In contrast, in experimental cultures, all entrepreneurs are willing to undertake risky projects that are more likely to fail, but provide great pay-off in case of success. Therefore, a failure event conveys less information about the quality of that entrepreneur, given the risk that was incurred. Hence, it makes less sense for stakeholders in this environment to penalize the entrepreneurs for failures, and the stigma is not attached to failed entrepreneurs.

We hybridize Landier's model with the literature on corporate entrepreneurship, which is defined as the process by which one or more individuals instigate a new organization or innovation within an existing organization (Sharma \& Chrisman, 1999, p. 18). Corporate entrepreneurship is characterized by innovative, experimental behaviors that have a high probability of failure (Miller, 1983; Thomke, 1998). Several researchers have already examined factors influencing the creation of a corporate "atmosphere" in which entrepreneurial behaviors may flourish or be suppressed and have identified a potential role for how failure is managed by an organization (Burgelman, 1983; Stevenson \& Jarillo, 1990). According to Farson and Keyes (2002), "[N]owhere is the fear of failure more intense and debilitating than in the competitive world of business, where a mistake can mean losing a bonus, a promotion, or even a job."

Prominent business leaders such as Jack Welch and Robert Shapiro appeared to have noted the effect of managers' fear of failure on their choices. During his tenure as CEO of Monsanto, Shapiro observed that employees were terrified of failing. Thus, he attempted to change perceptions about failure in order to encourage risk-taking. Jack Welch attempted to suppress fear of failure at General Electric by "rewarding failure." Such prominent efforts at managing failure in a positive way only serve to underline the reality that failure is stigmatized to some significant extent in many organizations. Yet, the mechanisms underlying this phenomenon are still not well understood. In a recent review, Kuratko and colleagues state that significant research questions remain; in particular, "research is needed to further clarify the linkage between the presence of specific qualities in an organizational context and individuals' (such as middle-level managers) decisions to act entrepreneurially" (Kuratko, Ireland, Covin, \& Hornsby, 2005, p. 711).

The following section introduces economic models of six cases that describe different entrepreneurial scenarios. The first case is the risk neutral selffinanced entrepreneur; it is a useful benchmark to compare with all other entrepreneurial situations. Next we analyze two cases where the entrepreneur depends on a venture capitalist to funds its initiative; in one case the financial market encourages experimentation, and in the other case the market is conservative, and readily penalizes failure. In the last three cases, the entrepreneur holds a long-term relationship with the corporation as an employee; each of the three cases evaluates different levels of tolerance regarding failure in the workplace.

\section{THE MODEL}

\subsection{Case I: Self-financed Entrepreneur}

We begin by considering a self-financed entrepreneur. This is a useful benchmark because the riskneutral, self-financed entrepreneur can make decisions unaffected by the market's imperfections.

In period 0 , the entrepreneur initiates a project that matures in period 2. Before the project starts, the entrepreneur expects the project to have probability $\pi_{\mathrm{H}}$ of being successful, $\pi_{M}$ of being mediocre and $\pi_{L}$ of being a total failure. These probabilities are true only if the entrepreneur is intrinsically competent - a fact unbeknownst to him. The manager may be competent (with probability $\theta$ ) or not. If he is not competent, the project will necessarily fail.

In period 1 , the manager receives a private signal high, medium or low probability $\left(p_{H^{\prime}} p_{M}\right.$ or $\left.p_{L}\right)$ - indi- 
cating the chances that the project will be successful. Each project has a start up cost $I$ and a possible successful outcome $X$. Therefore, projects are initiated if and only if:

$$
\theta\left(\pi_{H} p_{H}+\pi_{M} p_{M}\right) X-I>0 .
$$

Clearly, $p_{H}>p_{M}>p_{L}$. For example: if $p_{H}=80 \%, p_{M}=30 \%$ and $p_{L}=0 \%$, it means that the signal received in period 1 is that the project has $80 \%$ chance of being successful, or $30 \%$ chance of being successful, or that it will fail for sure.

A self-financed entrepreneur would certainly continue if he receives a signal $p_{H^{*}}$. It does not mean that the project will certainly succeed (that pesky $20 \%$ chance of failure still exists!). For example, if the project is worth $X=\$ 1$ Million, there is $p_{H}$ probability of getting that return, and $\left(1-p_{H}\right)$ probability of not gaining it. So, the expected value of the project at the time he receives the signal is $p_{H} X=\$ 800 \mathrm{k}$.

If the same entrepreneur receives a signal $p_{M^{\prime}}$ he may or may not continue. He knows that he is a good manager; otherwise, his signal would definitely be $p_{L}$. So, he might continue if the expected payoff is greater than the payoff of starting all over again with a new project, which may be more successful or not. Keeping with the example, the expected value of continuing this project is just $p_{M} X=\$ 300 \mathrm{k}$. If the self-funded entrepreneur abandons the project, he starts a new venture which requires another start up cost $I$. Let's say that $I=\$ 100 \mathrm{k}, \pi_{\mathrm{H}}=40 \%, \pi_{\mathrm{M}}=\pi_{\mathrm{L}}=30 \%$ and $\theta=40 \%$. This new venture would have an expected value of $\left(\pi_{H} p_{H}+\pi_{M} p_{M}\right) X-I=(32 \%+9 \%) \$ 1 \mathrm{M}-\$ 100 \mathrm{k}=\$ 310 \mathrm{~K}$ . Since continuing is worth $\$ 300 \mathrm{k}$, a risk-neutral, selffunded entrepreneur would prefer to start over.

If the entrepreneur receives a signal $p_{L}$, he is sure that the project is a dud. However, he does not know if it was his fault or not: the signal does not let him know if he is a competent manager. The pool of failed entrepre- neurs includes incompetent managers (Prob $=1-\theta$ ) and unlucky competent managers (Prob $=\theta \pi_{\mathrm{L}}$ ). By receiving the signal $p_{L}$, the probability that he is a competent manager is now reduced to:

$$
\theta^{\prime}=\theta \pi_{L} /\left(1-\theta+\theta \pi_{L}\right)<\theta
$$

An entrepreneur with prior entrepreneurial experience follows a different decision process. Figure 1 shows the transition diagram with four states of competence (reputation) and the probabilities to transition from one state to the next. All entrepreneurs are originated from state 0 (no prior experience). Initial experience moves them from state 0 to states $G$ (good manager), $U$ (good manager, but unknown to himself), or $B$ (bad manager, unknown to himself). After $n$ experiences, an entrepreneur that has seen $p_{H}$ or $p_{M}$ at least once knows that he is a good manager, and finds himself in state $G$. If the manager has only seen $p_{L^{\prime}}$, he does not know if he is good or not, and maybe he is in state $B$ (which he will never leave) or in state $U$ (which he might eventually leave, if he continues long enough). The probability that he is in state $U$, given that he has seen $p_{L}$ in all $n$ ventures that he has experienced, is:

$$
\theta_{n}^{\prime}=\theta \pi_{L}^{n} /\left(1-\theta+\theta \pi_{L}^{n}\right)<\theta^{\prime} .
$$

Clearly, as $n$ increases, $\theta^{\prime}$ approaches 0 . In our example, suppose that $n=3$, and the entrepreneur observed $\mathrm{p}_{\mathrm{L}}$ each time. Hence, $\theta_{n}^{\prime}=0.77 \%$. The risk-neutral entrepreneur initiates yet another project only if:

$$
\theta_{n}^{\prime}\left(\pi_{H} p_{H}+\pi_{M} p_{M}\right) X-I>0 .
$$

In summary, a self-financed entrepreneur, being risk neutral and without reputation concerns, eventually is able to make a sound estimate whether he is capable of leading an idea into a successful venture. Most important, this analysis indicates the value of the private information that the entrepreneur receives in the first few steps into the venture (period 1). 


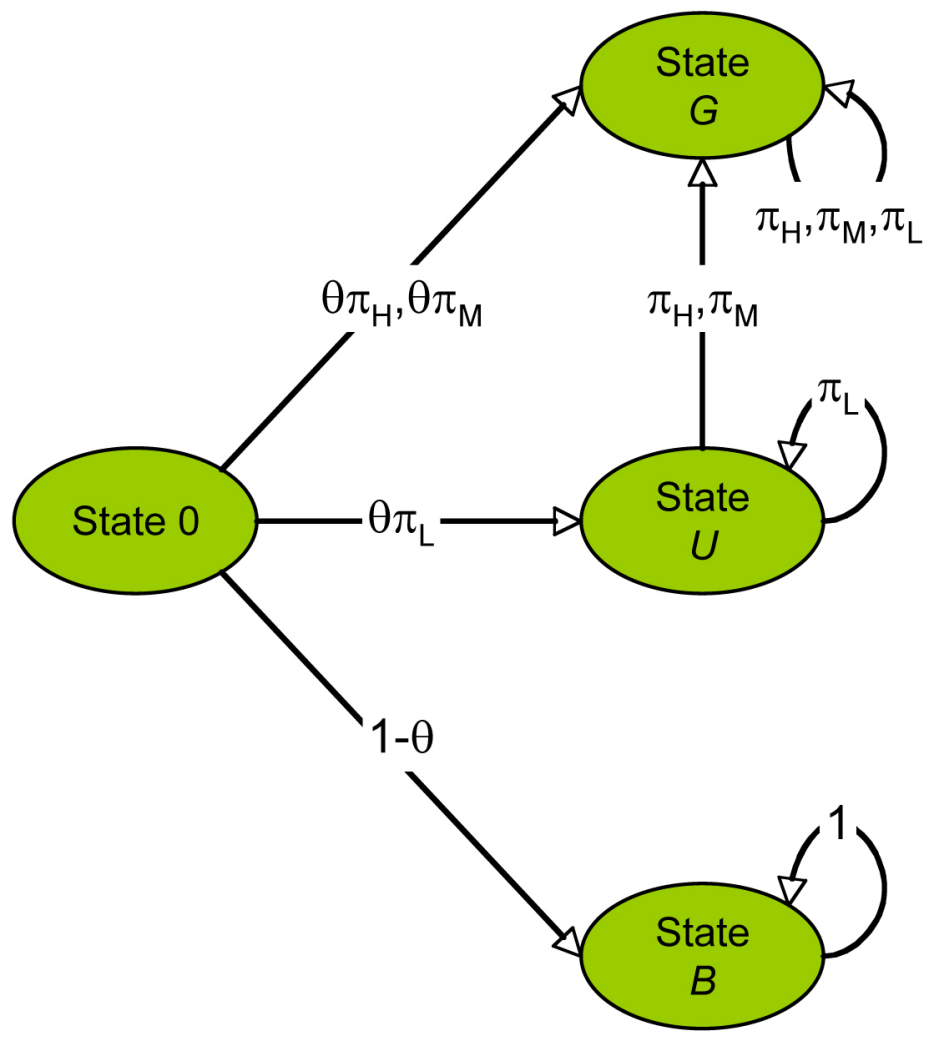

Figure 1. Transition Diagram (4 states)

\subsection{Case II: VC-funded Entrepreneur}

Here, the venture capitalist provides initial capital $I$ to fund a project with estimated earning potential $X .^{2}$ The venture capitalist receives a compensation $R$ if the project is successful and 0 if it fails. The entrepreneur keeps $X-R$ if successful and 0 otherwise. Entrepreneurs initiate projects if and only if:

$$
(X-R)>0 \text {. }
$$

The VC-funded entrepreneur has to deal with market imperfections because, unless he completes the project with some level of success, the VC never knows if he is competent or not. Moreover, the market wants to ensure that competent managers always complete projects with signal $p_{H}$ to prevent strange behaviors such as "compulsive entrepreneurship" (an abnormal situation when the entrepreneur takes greater pleasure to start a new project than to bring a good project to fruition). Also, the market wants the entrepreneur to treat projects with mediocre signal $p_{M}$ according to the typical willingness to take risk

2 Subcases II-A and II-B have been proposed by Landier (2005). They are here presented for completeness. in that market. The market induces this behavior by adjusting the cost of capital for previously failed entrepreneurs in period 2. If the cost of capital for failed entrepreneurs is $R^{\prime}$, he will continue only if:

$$
p_{M}(X-R)>\left(\pi_{H} p_{H}+\pi_{M} p_{M}\right)\left(X-R^{\prime}\right) .
$$

If the entrepreneur sees a signal $p_{L^{\prime}}$ he has no incentive to continue this venture, but he may consider starting a new venture if the cost of capital is less than its potential return $\left(X>R^{\prime}\right)$. Since the market cannot distinguish competent managers among entrepreneurs that failed voluntarily after receiving a mediocre signal and those that failed because they received a poor signal, all failed entrepreneurs are subject to the same cost of capital.

Next, we compare two types of venture capital market that differ according to their willingness to stigmatize or forgive failure.

\section{Subcase a) Conservative financial market}

The conservative market is defined as the one that imposes high cost of capital to failed entrepreneurs. Consequently, if the entrepreneur sees $p_{M^{\prime}}$ his reac- 
tion is to continue with the project - even though he knows that it will provide only mediocre returns. Otherwise, his next venture will be funded with expensive capital. That is, in this market:

$$
p_{M}\left(X-R_{C M}\right)>\left(\pi_{H} p_{H}+\pi_{M} p_{M}\right)\left(X-R_{C M}^{\prime}\right) .
$$

Landier recognizes this as an incentive compatibility constraint, meaning that $R^{\prime}$ is the venture capitalist's return on successful entrepreneurship that induces the correct behavior for this market.

The risk-neutral venture capitalist, not knowing if competent managers lead the projects that she funds, requires a return on investment coherent with the project's probability of success, considering the composition of the respective pools of managers:

$$
R_{C M}=\frac{I}{\left(p_{M} \pi_{M}+p_{H} \pi_{H}\right) \theta} \text { and } R_{C M}^{\prime}=\frac{I}{\left(p_{M} \pi_{M}+p_{H} \pi_{H}\right) \theta_{C M}^{\prime}}
$$

...where $\theta_{C M}$ is the probability (in the eyes of the VC) that a second-timer is a good manager. In this market, the pool of failed entrepreneurs contains just entrepreneurs that received the signal $p_{L}$. Hence, $\theta_{\mathrm{CM}}^{\prime}$ is:

$$
\theta_{C M}^{\prime}=\theta \pi_{L} /\left(1-\theta+\theta \pi_{L}\right)<\theta .
$$

Since $\theta_{C M}^{\prime}<\theta$, we have that $R_{C M}<R_{C M^{\prime}}^{\prime}$ which is consistent with the thesis that conservative markets assign higher cost of capital to failed entrepreneurs. However, if the entrepreneur sees $p_{L^{\prime}}$ he knows that the project will fail; so, he drops it. He may ask the VC to invest in another idea - if the cost of capital justifies. He starts a new project if $\theta_{C M}^{\prime}\left(\pi_{H} p_{H}+\pi_{M} p_{M}\right)\left(X-R_{C M}^{\prime}\right)>0$.

An entrepreneur with prior experience exposes the venture capitalist to a different decision process. If the venture capitalist has access to information about the final outcome of each of the entrepreneur's prior projects, the transition diagram in Figure 1 also represents the entrepreneur's states of competence (reputation) in a VC-funded conservative market. If the manager's record shows at least one successful event, he is in state G. If the record only shows failures, it implies that he has only seen $p_{L}$. Neither the VC nor the entrepreneur himself knows if he is good or not. The probability that he is in state $\mathrm{U}$, given that he has seen $p_{L}$ in all $\mathrm{n}$ ventures that he has experienced, is:

$$
\theta_{n, C M}^{\prime}=\theta \pi_{L}^{n} /\left(1-\theta+\theta \pi_{L}^{n}\right)<\theta_{C M}^{\prime} .
$$

To fund the next venture by experienced entrepreneurs, the risk-neutral VC expects as payoff

$$
R_{G, C M}=\frac{I}{p_{M} \pi_{M}+p_{H} \pi_{H}} \text { and } R_{n, C M}^{\prime}=\frac{I}{\left(p_{M} \pi_{M}+p_{H} \pi_{H}\right) \theta_{n, C M}^{\prime}}
$$

... where $R_{G, C M}$ is the payoff charged to a manager in state $G$, and $R_{n, \mathrm{CM}}^{\prime}$ is the payoff charged to a manager with $n$ experiences, none of them successful. Clearly,

$$
R_{G, C M}<R_{C M}<R_{C M}^{\prime}<R_{n, C M}^{\prime}
$$

$\ldots$ where $n>1$. In other words, the longer it takes for a manager to succeed, the higher is its cost of capital. Moreover, once the manager concludes a successful venture, his cost of capital drops to the lowest level in this market.

In order to allow some level of entrepreneurship in the conservative market, we must have $X>R_{G, C M}$ (new ventures are led by managers that gained successful experience in other markets, or by funding their own successful projects) or $X>R_{C M}$ (venture capitalists may fund inexperienced managers). As long as $X>R_{n, \mathrm{CM}^{\prime}}$ managers that failed their first $n$ projects may attempt yet another venture. The appendix summarizes the results in this and in other sections.

\section{Subcase b) Experimental financial market}

The experimental market encourages a high level of entrepreneurship. It does so by keeping the cost of capital low for failed entrepreneurs, so managers that observe less-than-stellar signals about their projects may be comfortable to abandon them to start new ventures that might provide better payoff.

If the entrepreneur sees the signal $p_{H^{\prime}}$ he is expected to complete the project - he cannot obtain a better signal than this. Yet, there is one valid concern in this situation: since the cost of capital for failed entrepreneurs is not punitive, the VC must adopt incentives that lead to the completion of projects that receive a good signal. Hence,

$$
p_{H}\left(X-R_{E M}\right)>\left(\pi_{H} p_{H}+\pi_{M} p_{M}\right)\left(X-R_{E M}^{\prime}\right) .
$$

Notice that by including the possibility of completing a mediocre project in second period, the inequality makes it even more profitable for the entrepreneur to continue the high-prospect project. If the signal is $p_{M^{\prime}}$ the entrepreneur in this market prefers to drop the project and start a new venture. To induce this behavior: 


$$
p_{M}\left(X-R_{E M}\right)<\left(\pi_{H} p_{H}+\pi_{M} p_{M}\right)\left(X-R_{E M}^{\prime}\right) .
$$

Again, the possibility of completing both highprospect and mediocre projects next period makes it even more profitable to abandon mediocre projects in the first attempt. Combining these two expressions, the incentive compatibility constraints in the experimental market are as follows:

$$
\frac{\pi_{H} p_{H}+\pi_{M} p_{M}}{p_{H}}<\frac{X-R_{E M}}{X-R_{E M}^{\prime}}<\frac{\pi_{H} p_{H}+\pi_{M} p_{M}}{p_{M}}
$$

Observe that the expression on the left is less than 1 , and the one on the right is greater than 1 . Hence, surprisingly, the cost of capital for failed entrepreneurs may or may not be higher than for first-timers: in this market, $R_{E M}$ may be greater than $R_{E M}^{\prime}$ or not. The pool of first-time failed entrepreneurs includes managers that chose to fail after seeing $p_{M}$ and managers that failed after seeing $p_{L}$ (because of competence or not). In the eyes of the $\mathrm{VC}$, the probability that a first-time failed manager is competent is:

$$
\theta_{E M}^{\prime}=\frac{\theta\left(1-\pi_{H}\right)}{\theta\left(1-\pi_{H}\right)+1-\theta}<\theta .
$$

The risk-neutral venture capitalist, not knowing if competent managers lead the projects that she funds, requires this return on investment:

$$
R_{E M}=\frac{I}{p_{H} \pi_{H} \theta} .
$$

The transition diagram in Figure 2 shows that, over time, the entrepreneur can be in five different states in the experimental market. After $n$ ventures, a manager that has seen $p_{H}$ at least once finds himself in state $(G, K)$ because he is good, and this is publicly known. If he has seen $p_{M}$ at least once but never saw $p_{H^{\prime}}$ he is in state $(G, U)$ because he is good, but he can't credibly convince the market that he is because he has never concluded a project. If he never observed $p_{H}$ nor $p_{M^{\prime}}$ he is in state $(U, U)$ if he is good, or in state $(B, U)$ if he is bad, but he can't possibly know which is true. To ensure that entrepreneurs in state $(G, K)$ always conclude high-prospect projects and always forego mediocre projects, the incentive compatibility constraints are:

$$
\begin{gathered}
p_{H}\left(X-R_{G, E M}^{m}\right)>\left(\pi_{H} p_{H}+\pi_{M} p_{M}\right)\left(X-R_{G, E M}^{m+1}\right) \text { and } \\
p_{M}\left(X-R_{G, E M}^{m}\right)<\left(\pi_{H} p_{H}+\pi_{M} p_{M}\right)\left(X-R_{G, E M}^{m+1}\right),
\end{gathered}
$$

... where $m$ is the number of failed ventures since the manager last experienced a successful project. These constraints simplify to:

$$
\frac{\pi_{H} p_{H}+\pi_{M} p_{M}}{p_{H}}<\frac{X-R_{G, E M}^{m}}{X-R_{G, E M}^{m+1}}<\frac{\pi_{H} p_{H}+\pi_{M} p_{M}}{p_{M}} .
$$

Since the entrepreneur concludes only those projects that have high prospects, the VC expects her return on investment from entrepreneurs in state $(G, K)$ to satisfy:

$$
R_{G, E M}^{m} \geq \frac{I}{p_{H} \pi_{H}}, \forall m .
$$

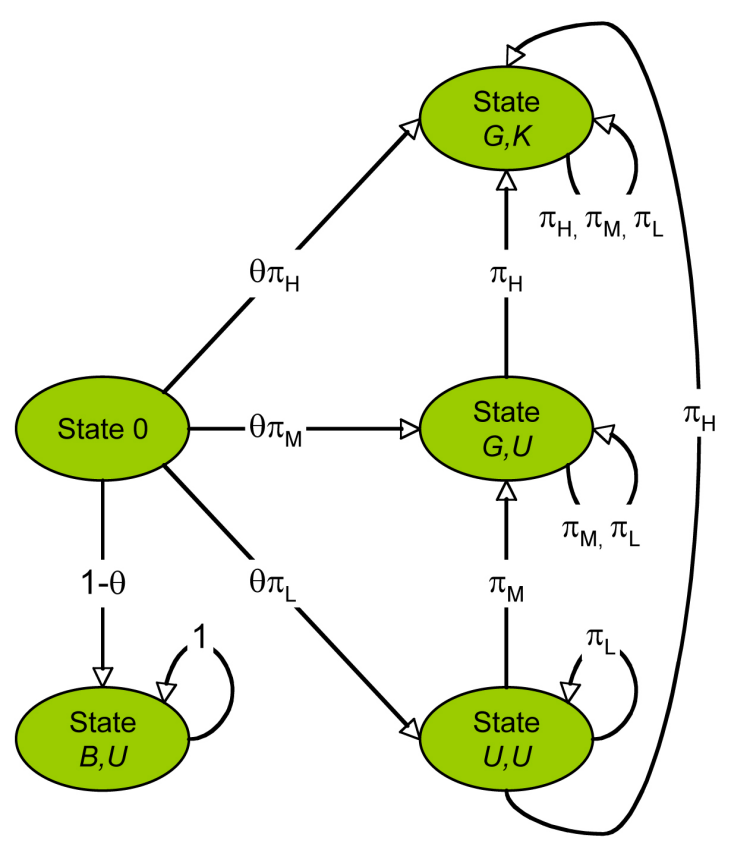

Figure 2. Transition Diagram (5 states)

If the entrepreneur has never completed a project, the VC does not know if he is competent (even if the entrepreneur once received a private signal indicating that a project had mediocre prospects, a signal available only to competent entrepreneurs). In the eyes of the $\mathrm{VC}$, the probability that a manager with $n$ prior experiences without success is indeed a competent manager is: 


$$
\theta_{n, E M}^{\prime}=\frac{\theta\left(1-\pi_{H}\right)^{n}}{\theta\left(1-\pi_{H}\right)^{n}+1-\theta}<\theta_{E M}^{\prime} .
$$

If the manager has observed $p_{M}$ at least once, he is in state $(G, U)$; he knows that he is competent for sure, but the market does not know. To ensure that he concludes high-prospect projects but abandons mediocre projects, the market imposes constraints that are similar to the ones for state $(G, K)$ :

$$
\begin{gathered}
p_{H}\left(X-R_{n, E M}^{\prime}\right)>\left(\pi_{H} p_{H}+\pi_{M} p_{M}\right)\left(X-R_{n+1, E M}^{\prime}\right) \text { and } \\
p_{M}\left(X-R_{n, E M}^{\prime}\right)<\left(\pi_{H} p_{H}+\pi_{M} p_{M}\right)\left(X-R_{n+1, E M}^{\prime}\right) .
\end{gathered}
$$

These incentive compatibility constraints simplify to:

$$
\frac{\pi_{H} p_{H}+\pi_{M} p_{M}}{p_{H}}<\frac{X-R_{n, E M}^{\prime}}{X-R_{n+1, E M}^{\prime}}<\frac{\pi_{H} p_{H}+\pi_{M} p_{M}}{p_{M}} .
$$

Moreover, the VC expects return on investments from entrepreneurs that are not in state $(G, K)$ to be:

$$
R_{n, E M}^{\prime} \geq \frac{I}{p_{H} \pi_{H} \theta_{n, E M}^{\prime}} .
$$

The manager that only received signal $p_{L}$ after $n$ experiences does not know if the projects failed because of him or not. His probability of being in state $(U, U)$ is:

$$
\theta_{n, L M}^{\prime}=\frac{\theta \pi_{L}^{n}}{\theta \pi_{L}^{n}+1-\theta}<\theta_{n, E M}^{\prime} .
$$

If he sees $p_{L}$ once again, he still doesn't know if he is a competent or a bad manager. He abandons and restarts a new venture because, according to the incentive compatibility constraints, $\left(X-R_{n+1, E M}^{\prime}\right)>0$, indicating that the venture capitalist is willing to fund another project at a cost that is acceptable to the entrepreneur. Hence, unlike those in the conservative market, entrepreneurs in the experimental market always have an opportunity to attempt a new venture, despite the number of failures they have experienced. ${ }^{3}$

This case explained the difference in the tolerance

3 This result is quite intriguing, but must be taken with a grain of salt. As it is currently modeled, the whole payoff for both the VC and the entrepreneur occurs at the end of the project, if it is successful. Hence, the entrepreneur's personal effort is not being considered. If his time and effort is included in the model as a reservation price, and since $\theta_{n} \rightarrow 0$ as $\mathrm{n}$ increases, we expect that after $n^{*}$ failures, the entrepreneur will choose not to invest more time on his very questionable entrepreneurial talent. to failure in different venture capital markets. As recently discussed in the media (The Economist, 2007), many European and Asian governments have poured substantial fortunes to create industrial clusters - usually located near a large university where innovation may be found - in an attempt to replicate the continued successful experience in the Silicon Valley. Similar effort is in progress in Russia (The Economist, 2010). However, while European venture capitalists risked only \$9B in new ventures in 2006, the American counterparts risked 5 times as much in the same period. These numbers indicates not just the difference in the willingness to take risk between the financial institutions in both regions, but also their willingness to accept entrepreneurs with failed experiences, curtailing or encouraging innovative ideas in each region. Hence, in addition to (or despite of) governmental incentives to encourage entrepreneurial activity, an over-arching entrepreneurial culture that tolerates failure is necessary to find societal entrepreneurial success.

\subsection{Case III: Corporate-funded Employee}

In this case, we introduce a corporation that invests an amount $I$ to launch a project under the leadership of an employee. Employee initiated projects are at the heart of the quality improvement or cost reduction efforts at General Electric, Wal-Mart, and many other organizations recognized for their "operational efficiency". If successful, both company and employee have positive payoff. For the corporation, the payoff $R$ is the project return. For the employee, the payoff $X$ could be a promotion, a raise or greater "reputation" among colleagues. Notice that in this environment, $R \gg X$, so we do not consider the impact of $X$ on $R$.

If the project is not successful, the company loses the initial investment, and the employee suffers a loss $-K$, which may be immaterial, damage to his reputation, loss of credibility among colleagues, demotion, or even loss of employment. A risk-neutral employee initiates his project if the expected value of his payoff satisfies

$$
\theta\left(\pi_{H} p_{H}+\pi_{M} p_{M}\right) X-\left(1-\theta\left(\pi_{H} p_{H}+\pi_{M} p_{M}\right)\right) K>0 .
$$

Hence, projects are initiated only if:

$$
\frac{\theta\left(\pi_{H} p_{H}+\pi_{M} p_{M}\right)}{1-\theta\left(\pi_{H} p_{H}+\pi_{M} p_{M}\right)}>\frac{K}{X} .
$$


The employee also has to deal with market imperfections because the employer does not know about his competence to complete a project until he has completed at least one. Like the VC, the corporation expects that all projects with high prospects are brought to completion, and that mediocre projects be handled according to the organization's willingness to accept risk. ${ }^{4}$

In period 0 , the employee initiates a project that matures in period 2. In period 1 , the employee receives a private signal $p$ about the project. The employee trades off the potential gain $(p X-(1-p) K)$ for continuing the project with the certain loss for abandoning it immediately $(-K)$. Consequently, the employee continues if $X>-K$, which is always true, as long as the signal $p$ is greater than $0 !^{5}$ Moreover, once the employee abandons or concludes his project, he may choose to take on another project with payoff space $\left(X, K^{\prime}\right)$. Whether the employee continues or foregoes the project upon receiving the signal depends on the signal received and on the corporation's tolerance to failure, which we discuss below.

\section{Subcase a) Experimental corporation}

We call experimental corporation one that encourages entrepreneurship from its employees, and is tolerant to unsuccessful initiatives. Consequently, if the employee receives a mediocre signal in period 1 , the employer expects him to abandon the project and start a new one. In order to induce this behavior, the reward for continuing the mediocre project should be less than the potential value of starting a new project. If the employee receives a signal $p_{M^{\prime}}$ he knows that he is competent. Hence, to induce abandonment and encourage the employee to restart at new project, we have that:

$p_{H} X-\left(1-p_{H}\right) K>\left(\pi_{H} p_{H}+\pi_{M} p_{M}\right) X-\left(1-\left(\pi_{H} p_{H}+\pi_{M} p_{M}\right)\right) K^{\prime}-K$.

If the employee receives a signal $p_{H^{\prime}}$ the employer expects him to continue the project, because the pay-

4 This is in stark contrast with the financier's recommendation that all projects with positive NPV should be brought to fruition... However, most corporations prefer not to engage all projects with positive NPV. Rather, the typical corporation limits the amount of debt that is committed in a given time period.

5 In fact, if the signal is $p=0$, the employee is indifferent between stopping and continuing a project that has no future. In practice, this type of masochism would probably not occur, since the manager would accrue no satisfaction by investing additional time and effort in a project that will certainly fail. To incorporate this dissatisfaction in the model, it suffices to make K marginally larger for projects starting in period 2. off of continuing a good project is greater than the payoff of abandoning it and starting a new venture. Hence, to induce continuation:

$p_{H} X-\left(1-p_{H}\right) K>\left(\pi_{H} p_{H}+\pi_{M} p_{M}\right) X-\left(1-\left(\pi_{H} p_{H}+\pi_{M} p_{M}\right)\right) K^{\prime}-K$.

Simplifying these two expressions leads to the incentive compatibility constraints in this scenario:

$$
\frac{p_{H}(X+K)+K^{\prime}}{\left(\pi_{H} p_{H}+\pi_{M} p_{M}\right)}>\left(X+K^{\prime}\right)>\frac{p_{M}(X+K)+K^{\prime}}{\left(\pi_{H} p_{H}+\pi_{M} p_{M}\right)}
$$

On the other hand, the employer does not know if a failed employee abandoned the project after seeing a mediocre signal, which means he is competent, or after receiving a low signal, which means his competency remains unproven. The risk-neutral employer, not knowing if competent employees lead the projects that she funds, requires that each venture meet the threshold:

$$
\frac{I}{R} \leq p_{H} \pi_{H} \theta
$$

The transition diagram in Figure 2 can also be used to describe the five states of a corporate entrepreneur in an experimental organization. After $n$ ventures, a manager that has seen $p_{H}$ at least once finds himself in state $(G, K)$ because he is good, and this is publicly known. To ensure that the entrepreneur always concludes high-prospect projects and always foregoes mediocre projects, the incentive compatibility constraints are:

$$
\begin{aligned}
& p_{H} X-\left(1-p_{H}\right) K_{G, E C}^{m}>\left(\pi_{H} p_{H}+\pi_{M} p_{M}\right) X-\left(1-\left(\pi_{H} p_{H}+\pi_{M} p_{M}\right)\right) K_{G, E C}^{m+1}-K_{G, E C}^{m} \text { and } \\
& p_{M} X-\left(1-p_{M}\right) K_{G, E C}^{m}<\left(\pi_{H} p_{H}+\pi_{M} p_{M}\right) X-\left(1-\left(\pi_{H} p_{H}+\pi_{M} p_{M}\right)\right) K_{G, E C}^{m+1}-K_{G, E C}^{m}
\end{aligned}
$$

... where $m$ is the number of failed ventures since the manager last experienced success. These constraints simplify to:

$$
\frac{p_{H}\left(X+K_{G, E C}^{m}\right)+K_{G, E C}^{m+1}}{\left(\pi_{H} p_{H}+\pi_{M} p_{M}\right)}>\left(X+K_{G, E C}^{m+1}\right)>\frac{p_{M}\left(X+K_{G, E C}^{m}\right)+K_{G, E C}^{m+1}}{\left(\pi_{H} p_{H}+\pi_{M} p_{M}\right)} .
$$

This incentive compatibility constraint applies both to managers that have experienced past success as well as to those that are observing $p_{H}$ for the first time. Since the employee concludes only those projects that have high prospects, the employer funds projects proposed by employees in state $(G, K)$ that satisfy:

$$
\frac{I}{R} \leq p_{H} \pi_{H}
$$


After $n$ - 1 attempts, if the employee has observed a signal $p_{M}$ at least once, but never observed $p_{H^{\prime}}$ he knows that he is competent, and he has just as much chance as any employee in state $(G, K)$ to manage a project successfully. However, he may have been stigmatized for his continued lack of success. To ensure that he continues to propose new projects, the experimental organization limits his stigma to:

$$
\frac{\left(\pi_{H} p_{H}+\pi_{M} p_{M}\right)}{1-\left(\pi_{H} p_{H}+\pi_{M} p_{M}\right)}>\frac{K_{n, E C}^{\prime}}{X} .
$$

This is the second incentive compatibility constraint in the experimental corporation. It ensures that employees in state $(G, U)$ have the opportunity to take on new projects. Finally, if the employee never observed $p_{H}$ nor $p_{M^{\prime}}$ he is in state $(U, U)$ if he is good, or in state $(B, U)$ if he is bad, but either information in unknown to him. He does not know if his projects failed because of him or not, and he suffers the unavoidable personal loss each time his project fails. His probability of being competent is:

$$
\theta_{n, L C}=\frac{\theta \pi_{L}^{n}}{\theta \pi_{L}^{n}+1-\theta}<\theta .
$$

Considering that his probability of being competent decreases with each attempt, the failed entrepreneur starts a new project only if:

$$
\frac{\theta_{n, L C}\left(\pi_{H} p_{H}+\pi_{M} p_{M}\right)}{1-\theta_{n, L C}\left(\pi_{H} p_{H}+\pi_{M} p_{M}\right)}>\frac{K_{n, E C}^{\prime}}{X} .
$$

Employees who have not yet concluded any projects are in state $(G, U),(U, U)$ or $(B, U)$, and the employer cannot distinguish them. In the eyes of the employer, the probability that one such employee is competent is:

$$
\theta_{n, E C}=\frac{\theta\left(\pi_{M}+\pi_{L}\right)^{n}}{\theta\left(\pi_{M}+\pi_{L}\right)^{n}+1-\theta}<\theta
$$

Hence, the employer funds projects initiated by employees that are not in state $(G, K)$, and that have failed $n$ projects, if they satisfy:

$$
\frac{I}{R} \leq p_{H} \pi_{H} \theta_{n, E C}, \forall n
$$

This threshold limits the scope of new ventures and the number of attempts by employees without suc- cessful experience. Yet, this model shows tolerance from the employer that keeps encouraging employees even after they have encountered failure more than once. This tolerance is an important ingredient in the experimental organization, which reassures the innovative employees that they need not be afraid of bringing their ideas forward because, if the idea is funded but it does not succeed, their careers are not in jeopardy. The signals indicate that breakthrough innovations are more important for the corporation than gradual improvements that can be achieved with "safe" ideas.

\section{Subcase b) Conservative corporation}

A conservative corporation is defined as one that avoids high-risk projects. It entertains and sponsors innovative ideas as long as they are "safe" to deliver. In this environment, an employee will propose ideas that can be easily executed and supports the status quo. The project is initiated in period 0 to conclude in period 2. If the employee observes the private signal $p_{H}$ or $p_{M}$ in period 1 , he is expected to complete the project rather than taking on another venture. Because his career is on the line, his personal payoff is greater by continuing the venture than by abandoning it, which leads to:

$p_{M} X-\left(1-p_{M}\right) K>\left(\pi_{H} p_{H}+\pi_{M} p_{M}\right) X-\left(1-\left(\pi_{H} p_{H}+\pi_{M} p_{M}\right)\right) K^{\prime}-K$.

Consequently, the first incentive compatibility constraint is:

$$
p_{M}(X+K)>\left(\pi_{H} p_{H}+\pi_{M} p_{M}\right)\left(X+K^{\prime}\right)-K^{\prime} .
$$

With this constraint, an employee that observes $p_{H}$ in period 1 would consider nothing other than continuing his project. However, if the employee observes $p_{L^{\prime}}$ he abandons and suffers personal loss, but he may still engage in a new project. The riskneutral employer, not knowing if inexperienced employees are competent, requires that their ventures meet the threshold:

$$
\frac{I}{R} \leq \theta\left(p_{H} \pi_{H}+p_{M} \pi_{M}\right) .
$$

The transition diagram in Figure 1 represents the four states of competence in conservative corporate entrepreneurship. If the manager's records show at least one successful event, he is in state G. Moreover, he is expected to finish all projects for which he gets a private signal $p_{H}$ or $p_{M}$ in period 1 . Thus: 


$$
p_{M}\left(X+K_{G, C C}^{m}\right)>\left(\pi_{H} p_{H}+\pi_{M} p_{M}\right)\left(X+K_{G, C C}^{m+1}\right)-K_{G, C C}^{m+1}
$$

... where $m$ is the number of consecutive failures since the last success. Since the employer concludes all projects that have high or mediocre prospects, the employer associates employees in state $G$ with the risk level given by:

$$
\frac{I}{R} \leq\left(p_{H} \pi_{H}+p_{M} \pi_{M}\right)
$$

Even conservative organization want to ensure some level of entrepreneurship. This is achieved by constraining the stigma to:

$$
\frac{\left(\pi_{H} p_{H}+\pi_{M} p_{M}\right)}{1-\left(\pi_{H} p_{H}+\pi_{M} p_{M}\right)}>\frac{K_{G, C C}^{n}}{X}, \forall n .
$$

If the records show that an employee has observed only failures, neither he nor the employer knows if he is good or not. The probability that he is in state $U$ (possibly competent), given that he has seen $p_{L}$ in all $n$ ventures that he has experienced, is:

$$
\theta_{n, C C}=\frac{\theta \pi_{L}^{n}}{\theta \pi_{L}^{n}+1-\theta}<\theta
$$

Considering that the probability of being competent decreases with each failed attempt, the failed entrepreneur starts a new project only if:

$$
\frac{\theta_{n, C C}\left(\pi_{H} p_{H}+\pi_{M} p_{M}\right)}{1-\theta_{n, C C}\left(\pi_{H} p_{H}+\pi_{M} p_{M}\right)}>\frac{K_{n, C C}^{\prime}}{X} .
$$

To fund the next venture suggested by experienced employees that are not in state G, the employer requires that the enterprise meet the threshold:

$$
\frac{I}{R} \leq p_{H} \pi_{H} \theta_{n, C C}, \forall n
$$

Corporations that fit this model usually curtail their access to leapfrog innovation. This is not necessarily bad, if the organization operates in a mature industry where leapfrog opportunities are extremely rare. By establishing greater hurdles to innovation, the organization is forcing the employees to contribute within the boundaries of known technologies or methods of gradual (or marginal) improvements.

\section{Subcase c) Ultra-conservative corporation}

We call ultra-conservative the corporation with extremely low tolerance for project failures. In such an environment, employees that failed once face high hurdles to lead future projects. This type of organization would stigmatize failed managers, making sure that, if they observe $p_{M^{\prime}}$ they complete the project; and if they observe $p_{L^{\prime}}$ future projects won't receive corporate support. Obviously, some entrepreneurship is desirable, so successful employees are well-rewarded for completing their projects.

If an employee observes $p_{M^{\prime}}$ he avoids the stigma of failure and continues his project. Continuing the project has a better personal payoff than abandoning:

$$
p_{M}(X+K)>\left(\pi_{H} p_{H}+\pi_{M} p_{M}\right)\left(X+K^{\prime}\right)-K^{\prime} .
$$

This incentive compatibility constraint is similar to the one in the conservative corporation. The risk-neutral employer, not knowing if competent employees lead the projects that she funds, requires that ventures by inexperienced managers meet the threshold:

$$
\frac{I}{R} \leq \theta\left(p_{H} \pi_{H}+p_{M} \pi_{M}\right)
$$

Likewise, a manager that observes $p_{L}$ suffers personal loss $(-K)$ and abandons the project. The probability that he is a competent employee is:

$$
\theta_{U C}^{\prime}=\frac{\theta \pi_{L}}{\theta \pi_{L}+1-\theta}<\theta
$$

To ensure that the failed employee does not initiate a new venture, his personal payoff in a second attempt must be negative. This is achieved by setting a high stigma for failing a project a second time $\left(K^{\prime}\right)$, which is constrained by the expression:

$$
\frac{\theta_{U C}^{\prime}\left(\pi_{H} p_{H}+\pi_{M} p_{M}\right)}{1-\theta_{U C}^{\prime}\left(\pi_{H} p_{H}+\pi_{M} p_{M}\right)}<\frac{K^{\prime}}{X} .
$$

For the ultra-conservative employer, the implicit risk in projects led by managers that have failed is:

$$
\frac{I}{R}>\theta_{U C}^{\prime}\left(p_{H} \pi_{H}+p_{M} \pi_{M}\right)
$$


This scenario can be represented by the three-state transition diagram in Figure 3, in which employees move from state 0 (inexperienced) to state $G$ (good) or state $S$ (stigmatized). Proposing projects in this environment is a dangerous gamble since, after a sufficient number of experiences, all managers eventually fail and become stigmatized. To avoid this predicament, employees avoid projects with any risk level: they become bureaucratic and limit themselves to the most basic innovations (high $\pi_{\mathrm{H}}$ ) or those with least relevance and lowest consequence (low $K$ ). An organization might choose this approach to innovation if it operates in very mature markets, or in the presence of a management team that lacks vision.

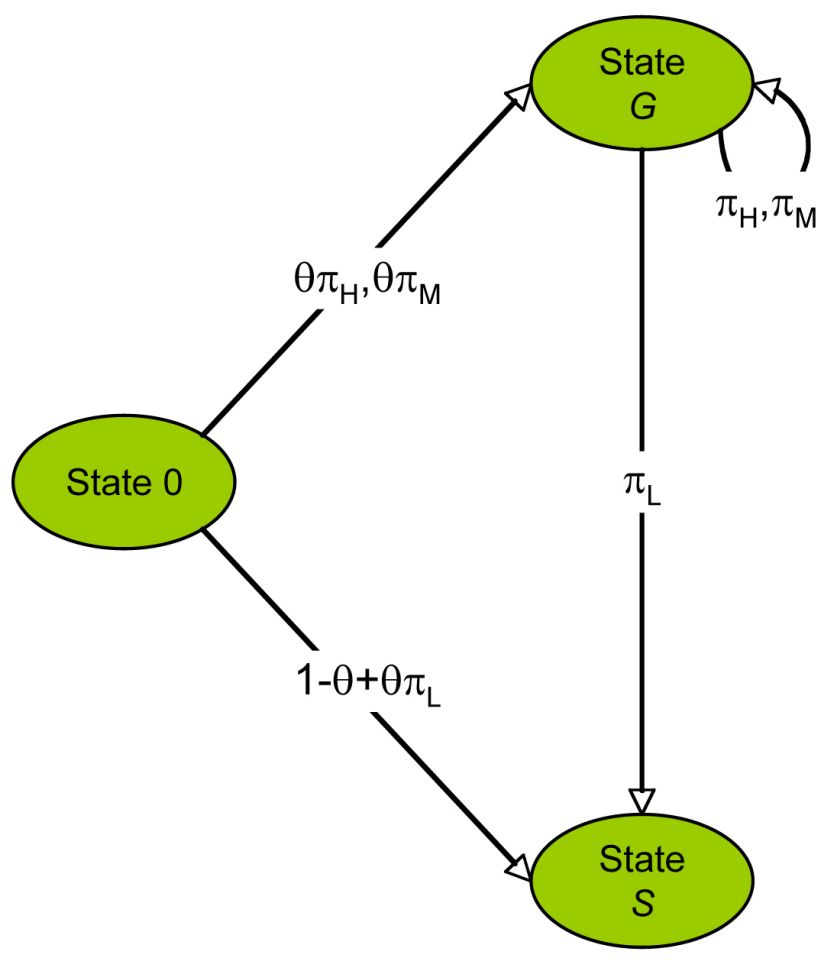

Figure 3. Transition Diagram (3 states)

\section{RESEARCH IMPLICATIONS}

\subsection{Corporate culture and incentives for corporate entrepreneurship}

Our model is related to the strategic management literature on corporate entrepreneurship. Research on corporate entrepreneurship suggests that, in some environments, a significant relationship exists between entrepreneurial behavior and performance in organizations both large and small (Zahra \& Covin, 1995). Whereas Landier's concern is with the entrepreneurial culture of industries and regions, a central concern in strategic management theory is the role of corporate culture in nurturing employee behaviors that may ultimately lead to competitive advantage (Barney, 1991). Corporate culture may be viewed as, "a substitute for explicit communication. That is, culture is an unspoken language giving directives to the members of an organization" (Cremer, 1993). Burgelman (1983) suggests that senior management is influential in setting the environment for employee behaviors by how they manage failure in their organizations. In his formulation, Burgelman (1983, p. 1361) asserts, "Autonomous strategic behavior emerges, by definition, spontaneously. Corporate management thus need not encourage entrepreneurship; it need only make sure not to suppress it." 6 Other scholars have also argued that core organizational values and beliefs play a fundamental role in nurturing corporate entrepreneurship (Guth \& Ginsberg, 1990; Zahra, 1991). Stevenson and Jarillo (1990, p. 24) argue that, "the treatment of failure would appear to be a critical component of the necessary motivation to pursue opportunity." Indeed, they hypothesized that organizations that attach less negative consequences to failure would exhibit more entrepreneurial behaviors. In an experimental study, Lee, Edmondson, Thomke, and Worline (2004) have identified tolerance for failure is indeed an important variable influencing employees' willingness to engage in experimental behaviors.

Our study contributes to this literature by showing that a particular aspect of corporate culture (the extent to which the culture stigmatizes failure) can be modeled as a relatively simple information asymmetry problem as proposed by Landier (2005). The central insight generated in Landier's paper is that multiple equilibria may arise corresponding to different attitudes of entrepreneurs and capital markets towards entrepreneurial failure. Landier's model is supported by an empirical study by Bengtsson (2005), who examined data on the restart behavior of failed entrepreneurs in different geographies. Bengtsson found that the disproportionately large amount of venture capital activity in California could partly be explained by Californian investors attaching a lower stigma to failed entrepreneurs. Landier's paper also corresponds with anecdotal data on the role of the stigma of failure in different geographies and industries, such as differences between investor attitudes towards failure in the US, France and Japan.

A good test anecdote for our model may be found in reports about Jeff Immelt's efforts to transform

6 Emphasis added. 
GE into a "corporate innovation machine". Despite his predecessor's best efforts, Immelt inherited from Jack Welch an organization in which it appears that people are still afraid of undertaking risky, innovative behaviors. According to a Business Week interview with the new boss, "In his GE, the new imperatives are risk-taking, sophisticated marketing, and above all innovation." Accordingly, Immelt has told his top management team that, "You're not going to stick around this place and not take bets." Risking failure is inherent in taking bets on implementing innovations. However, under Welch's leadership, people were rewarded above all for making their numbers (mainly through cost cutting). This allowed GE to be the model of steady earnings increases and continuous improvement (in line with its Six Sigma initiatives). But the culture of "make your numbers or else" is antithetical to the cultural context required to encourage employees to try out entrepreneurial gambits that might deliver innovations. After all, cultures and policies that above all reward managers that make their numbers are just the kinds of cultures that bust people for failing. Recognizing the important influence of the organizational context for risk taking, Immelt has started "pushing for a cultural revolution." (Business Week, 2005).

\subsection{Incubating new business initiatives as separate entities}

Our model also contributes to the literature regarding when innovations are commercialized within established organizations and when they are commercialized using corporate ventures that are standalone divisions of a corporation (Christensen, 1997). In recent years, a literature that addresses methods of commercializing innovations was developed (Gans \& Stern, 2002; Cassiman \& Ueda, 2006; Hellmann, 2007; Klepper \& Sleeper, 2005). The underlying question is if an innovation is instigated by an existing organization or if it is commercialized by an independent start-up. However, there is also the related question of when (and why) an existing organization chooses to set-up a separate, wholly-owned venture for the commercialization of a new business idea, rather than to develop the new business within its existing organizational infrastructure. For instance, when IBM developed the PC, it established a new venture based in Florida, away from the parent company infrastructure in New Jersey. Similarly, Lockheed's famous skunk works was deliberately set-up as an independent venture outside the corporate organization, albeit wholly owned by the parent. Our model suggests one possible explanation for such decisions: the independently managed organizations are free to develop their own (more experimental) culture, less encumbered by the (conservative) culture of the parent organization. As such, they can develop an appropriate cultural regime that includes different expectations about the way to treat failure. This suggests that partitioning corporations into divisions may sometimes be motivated by efforts to establish different cultures with regard to failure management. To use an analogy, corporations may have their own Californias (i.e., divisions that attach a low stigma to failure), and they may have their Japans (i.e., divisions that strongly penalize failure). Initiatives that support minor improvements would be implemented within the low-risk divisions. High-risk initiatives that induce major process redesign would be tested within high risk divisions.

\subsection{Developing entrepreneurship inside organiza- tions}

The existence of a cognitive basis for domain-specific expertise (as delineated by Baron \& Ensley, 2006; Mitchell, Smith, Seawright, \& Morse, 2000; Sarasvathy, 2001) suggests that entrepreneurial success (especially over the course of several ventures or an individual's career) may be a function of skill rather than luck. If this is the case, could there be ways of evaluating entrepreneurial talent directly, rather than relying on vicarious inferences drawn from the success or failure of entrepreneurial ventures? Who would have the strongest incentives to invest in improving the independent evaluation of entrepreneurial ability? Are there coordination difficulties among entrepreneurs and evaluators that result in path-dependence in the development of entrepreneurial talent in a corporation?

Per our previous remarks, in Landier's formulation, stigma of failure is an informational problem. Like many other informational problems, there may be multiple ways of - at least partially - solving this problem. Organizations (such as corporations or, in the case of independent entrepreneurship, venture capitalists) may be able to improve their screening processes by investing in formal evaluation processes that enable them to more accurately assess the entrepreneurial abilities of individuals independently of success or failure in past ventures. Formal organizational structures, such as human resources departments, also have the authority to directly observe individuals and collect significant quantities 
of data about them (for example, using 360-degree evaluation processes). Even venture capitalists may develop skills in screening and evaluating entrepreneurial talent, independent of the particular investment opportunities offered to them.

One upshot of our model is that, to the extent that corporations can lower the cost of evaluating entrepreneurial skill levels, direct evaluation may substitute the indirect inferences stakeholders draw from venture failure about the entrepreneurial skills and abilities of individuals. One can infer from our model that a change in the cost of evaluation technologies would lead to different "cultural" equilibriums in organizations, developing corporate cultures that would be more accepting of entrepreneurial failure. If corporations could better identify high-ability individuals who failed in previous ventures, they could offer them a lower cost of capital in future ventures. This would encourage more innovation from skilled employees and create value for the firm.

There are, of course, several problems in investing in screening entrepreneurial skills. One is that before a corporation can accurately identify employees with entrepreneurial skills, they need managers who are themselves entrepreneurially skilled. A recent paper by Bernhardt, Hughson, and Kutsoati (2006) studies the strategic incentives that this creates. To summarize, workers are likely to distort investments toward skills that a firm's managers can best evaluate (as well as attempt to manipulate evaluator's judgments about their skills by their choice of project and by manipulating perceptions about their role in project successes and failures - Amit, Glosten, \& Muller, 1990; Holmstrom, 1999). In a dynamic context (in which workers one day become managers), the population of skills in an organization may skew over time. This may explain the low levels of entrepreneurship in many corporations: it suggests that the development of corporate entrepreneurship depends on having a combination of managers (skilled entrepreneurial evaluation) and employees (skilled entrepreneurship).

Another closely related issue is identified in a study by Gromb and Scharfstein (2003). It concerns the reassignment of failed "intrapreneurs" within a corporation. In their model, the critical assumption is that firms and markets differ in their ability to observe and retain information about the skills and abilities of individuals. Intrapreneurship enables firms to learn about individuals and redeploy failed, but able, managers to new projects within the firm. Poorly performing intrapreneurs are stigmatized: no one wants to hire them because those that are on the job market are ones that established firms have chosen not to retain. By contrast, being a failed independent entrepreneur is not as bad a signal as that associated with being fired from an established firm: independent failure does not convey as much information about the ability of the entrepreneur. Gromb and Scharfstein's model thus adds another dimension to the analysis we develop in this paper by highlighting the role that more- or less-accurate information regimes may have in stigmatizing individuals. Again, the underlying insight is that noisy information regimes (i.e., experimental ones) are less likely to result in a stigma of failure than regimes in which inferences about individual abilities can be made more accurately (i.e., more conservative regimes).

\section{IMPLICATIONS FOR PRACTICE}

The central message of this study for practice is quite intuitive and quickly summarized. New technologies vary in their implementation risks and organizations vary in how they treat managers who fail. Conservative organizational cultures penalize managers for failing. This creates incentives for managers to pursue safe projects that are unlikely to fail, and avoid taking risks in projects. This makes it difficult for the organization to projects associated with cutting edge new technologies. At the limit, ultra-conservative organizations may drive out risk-taking behavior altogether. General Motors, usually described as a conservative organization, did not fully just-in-time methods until the year 2000 (Glass, 2010). Glass explains General Motors' recent worries in light of its low corporate entrepreneurship that led to the inability to nurture new ideas, even when shown evidence of success, which led to poor operations.

To nurture new technologies organizations need to support some level of risk, by developing experimental cultures in which failure isn't actively penalized. This is an easy suggestion to make, but much harder to actually execute. An important implication for practicing managers is that in the context of the generally conservative cultures of many well-established organizations, managers might be wise to heed to the potential stigma from being associated with projects that have a high (ex ante) risk of failure. They may do this in some subtle and baroque ways, as well as in candid ways. In either case, a major implication is that organizational culture matters 
because it influences the choices that project managers make. Faced with the unsavory prospect of being penalized, managers are more likely to choose safe projects and shun risky decisions. Several observable behaviors would be consistent with the incentive structure that exists in a generally conservative organizational context (what we have modeled as the "conservative corporation"), such as:

1. All other things equal, project choice tends to favor the implementation of "safe" projects rather than go "out on a limb" to implement risky ones with unproven technology; the result for the organization as a whole is that its portfolio of future projects will contain mostly low-risk bets that lead to moderate returns. They will rarely contain risky projects with greater organizational pay-offs.

2. All other things equal, individual project management may involve too much (rather than too little) risk analysis and too many risk mitigation procedures. Conservatism with regard to risk may benefit the project manager, not the organization. This encourages projects management processes that are potentially too conservative in the context of the organization's entire portfolio of projects. Although the organization has greater means to balance its portfolio of risky bets than the individual, risk is avoided at the individual level.

3. All other things equal, project managers should engage projects whose success or failure is transparently linked with external variables. This would reduce the risk of being blamed for the project failure by other organizational actors, generating trade-offs between the incentives to bring projects more firmly under the control of project managers in order to manage them effectively, and incentives to let the fortunes of a project be driven by visible external stakeholders and exogenous public processes.

Many of the effects highlighted in this study are quite subtle and evade easy empirical detection, though we believe they are nonetheless realistic. For example, take project delays. Regardless of the actual reasons for delay (and there may be many) what we have observed how easily extraneous factors can be summoned up by project managers to justify them. This is precisely the kind of phenomenon we would anticipate based on our model's results.

Not surprisingly, greater tolerance for failure leads entrepreneurs to take more risks, both in the financial market and in the workplace. What is perhaps less intuitive, however, is that organizations with greater tolerance for failure will generally see more frequent improvement of their processes, which explains the continuous success in quality improvement and cost reduction in some corporations.

This line of argument leads us to believe that our results may have strong practical application in the public sector as well as in private sector organizations. According to a popular resource on corporate entrepreneurship (Morris and Kuratko, 2002), the term entrepreneurship has appeared with increasing frequency in the public administration literature since the early 1990s. However, public organizations typically exhibit a cluster of tightly connected and highly conservative behaviors and therefore would be expected to stigmatize failure in significant ways. Indeed, according to Morris and Kuratko, "There is also career-related risk in the public sector, for although it is difficult to fire people, advancement can be hampered by visible failures" (p. 309). Our model indicates that ultra-conservative organizations and government institutions are usually characterized as such; they will drive out entrepreneurial behavior since after a sufficient number of trials, all managers will eventually fail and become stigmatized. Hence, managers will propose only the easiest or least significant innovations; in other words, such organizations become bureaucratic.

To conclude, in this paper we have provided a model that supports a contingent view of stigma of failure in organizations. It explains why the creation of innovative products and processes requires a forgiving culture that encourages experimentation, which brings both success and failure as the organization develops superior operational performance. The core results of our paper in fact rest on very simple and intuitive assumptions about human behavior: that people take context into account as they watch each other and make attributes about the quality of each other's skills. They then use this information to form judgments about who is a great project manager and who is a failure, and how these individuals should be treated. Because our model is contingent, it supports two types of accounts of organizations that have emerged in contemporary society: both those (such as Scott Sandage's historical/cultural account - Sandage, 2005) that suggest stigma of failure to be a fundamental (albeit socially constructed) characteristic of culture that cannot easily be escaped by modern organizations; as well as those that suggest that in some organizations failure might be (even if just occasionally) worn as a badge of honor. 


\section{REFERENCES}

Amit, A., Glosten, L., \& Muller, E. (1990). Entrepreneurial ability, venture investments and risk sharing. Management Science, 36(10), 1232-1245.

Barney, J.B. (1991). Firm resources and sustained competitive advantage. Journal of Management, 17, 99 - 120.

Baron, R.A., \& Ensley, M.D. (2006). Opportunity recognition as the detection of meaningful patterns: Evidence from comparisons of novice and experienced entrepreneurs. Management Science, 52(9), 1331-1344.

Bengtsson, O. (2005). Investor attitudes and the supply of capital: Are venture capitalists in California more forgiving? (Working paper). Evanston, IL: Northwestern University.

Bernhardt, D., Hughson, E., \& Kutsoati, E. (2006). The evolution of managerial expertise: How corporate culture can run amok. American Economic Review, 96(1), 195-221.

Burgelman, R.A. (1983). Corporate entrepreneurship and strategic management: Insights from a process study. Management Science, 29(12), 1349-1364.

Business Week (2005). The Immelt Revolution. March 28, 2005.

Cassiman, B., \& Ueda, M. (2006). Optimal project rejection and new firm start-ups. Management Science, (52)2, 262-275.

Christensen, C. (1997). The innovator's dilemma. Cambridge, MA: Harvard Business School Press.

Crémer, J. (1993). Corporate culture and shared knowledge. Industrial and Corporate Change, 2, 351-386.

Dombrowski, P. and Gholz, E., 2006. Buying Military Transformation: Technological Innovation and the Defense Industry. New York: Columbia University Press.

Farson, R., \& Keyes, R. (2002). The failure-tolerant leader. Harvard Business Review, 80(8), 64-75.

Gans, J.S., \& Stern, S. (2002). The product market and the market for "Ideas": Commercialization strategies for technology entrepreneurs. Research Policy, 1441(32), 333-350.

GAO, 2005. Better Strategic Planning Can Help DoD RFID Program. September 16, 2005

Glass, Ira (2010). NUMMI. In This American Life, episode 403, Originally aired March $26^{\text {th }}, 2010$. Accessed on April $26^{\text {th }}$, 2010 from http://www.thisamericanlife.org/radio-archives/ episode/403/nummi. National Public Radio: Chicago.

Goffman, E. (1963). Stigma: Notes on the management of spoiled identity. Engelwood Cliffs: Simon and Schuster.

Gromb, D., \& Scharfstein, D. (2003). Entrepreneurship in equilibrium (Working paper). Cambridge, MA: MIT.

Guth, W.D., \& Ginsberg, A. (1990). Guest editors' introduction: Corporate entrepreneurship. Strategic Management Journal, 11, 5-15.

Hellmann, T. (2007). When do employees become entrepreneurs? Management Science, 53(6): 919-933.

Holmstrom, B. (1999). Managerial incentive problems: A dynamic perspective. Review of Economic Studies, 66, 169-182.
Kuratko, D.F., Ireland, R.D., Covin, J.G., \& Hornsby, J.S. (2005, November). A model of middle-level managers' entrepreneurial behavior. Entrepreneurship Theory and Practice, (), 699-716.

Kuratko, D.F., Montagno, R.V., \& Hornsby, J.S. (1990). Developing an intrapreneurial assessment instrument for an effective corporate entrepreneurial environment. Strategic Management Journal, 11, 49-58.

Landier, A. (2005). Entrepreneurship and the stigma of failure (Working paper). New York City: Stern School of Business.

Lee, F. Edmondson, A.C., Thomke, S., \& Worline, M. (2004). The mixed effects of inconsistency on experimentation in organizations. Organization Science, 15(3), 310-326.

Miller, D. (1983). The correlates of entrepreneurship in three types of firms. Management Science, 29(7), 770-791.

Mitchell, R.K., Smith, B., Seawright, K.W., \& Morse, E.A. (2000) Cross-cultural cognitions and the venture creation decision. Academy of Management Journal, 43(5), 974-993.

Morris, M.H., \& Kuratko, D.F. (2002). Corporate entrepreneurship: Entrepreneurial development within organizations. Winfield, KS: South-Western College Publications.

Sandage, S., 2005. Born Losers. Boston: Harvard University Press.

Sarasvathy, S.D. (2001). Causation and effectuation: Toward a theoretical shift from economic inevitability to entrepreneurial contingency. Academy of Management Review, 26(2), 243.

Saxenian, A. (1994). Regional advantage: Culture and competition in Silicon Valley and Route128. Cambridge, MA: Harvard University Press.

Sharma, P., \& Chrisman, J.J. (1999). Toward a reconciliation of the definitional issues in the field of corporate entrepreneurship. Entrepreneurship Theory and Practice, 23(3):11-28.

Stevenson, H., \& Jarillo, J.C. (1990). A paradigm for entrepreneurship: Entrepreneurial. management. Strategic Management Journal, 11, 17-27.

Sutton, R.I., \& Callahan, A.L. (1987). The stigma of bankruptcy: Spoiled organizational image and its management. Academy of Management Journal, 30(3), 405-436.

The Economist (2007). Something new under the sun: A special report on innovation. October 13th 2007. London: The Economist

The Economist (2010). Modernising Russia: Another great leap forward? March $11^{\text {th }}, 2010$. London: The Economist

Thomke, S.H. (1998). Managing experimentation in the design of new products. Management Science, 44(6), 743-762.

Williamson, O.E. (1985). The economic institutions of capitalism. New York: Free Press.

Zahra, S.A., \& Covin, J.C. (1995). Contextual Influences on the corporate entrepreneurship-performance relationship: A longitudinal analysis. Journal of Business Venturing, 10, 43-58.

Zahra, S.A. (1991). Predictors and financial outcomes of corporate entrepreneurship: An exploratory study. Journal of Business Venturing, 6, 259-285. 


\section{AUTHOR'S BIOGRAPHY}

Geraldo Ferrer is an Associate Professor of Operations Management at the Naval Postgraduate School. Prior to joining NPS, he was in the faculty of the Kenan-Flagler Business School at the University of North Carolina. His areas of expertise include global operations, supply chain management, sustainable technologies, product stewardship, reverse logistics and remanufacturing. He has also studied the reverse logistics required in recycling and remanufacturing operations, and inventory problems affecting products made in small batches for frequent deliveries.

Dr. Ferrer serves as reviewer in many academic journals, the National Science Foundation and the Social Sciences and Humanities Council of Canada. He received his PhD in Technology Management from INSEAD, his MBA from Dartmouth College, a mechanical engineering degree from the Military Institute of Engineering in Rio de Janeiro and a BA in Business Administration from Federal University of Rio de Janeiro. He was founder and director of Superserv Ltd., a company that promoted technology transfer ventures between North American and Brazilian business, introducing innovative technology products for the petroleum industry.

Nick Dew is an assistant professor in the Graduate School of Business and Public Policy at the Naval Postgraduate School, Monterey, CA. Nick has a Ph.D. in management from the University of Virginia, and an MBA from the Darden Business School, as well as a BA in history from the University of York in the U.K. Before joining academia, Nick worked in strategic management and sales \& marketing for British Petroleum, Europe's largest company, including a two year assignment in BP headquarters and a three-year international assignment in Southeast Asia.

Nick joined the faculty at the Naval Postgraduate School in 2003 where he teaches strategic management in the MBA program. He researches the evolution of the RFID (radio frequency identification) industry and entrepreneurial decision making. His work has appeared in the Journal of Evolutionary Economics, the Journal of Business Venturing, the International Journal of Entrepreneurship and Innovation and the Scandanavian Journal of Management. 
APPENDIX: SUMMARY OF RESULTS

Subcase II-B: VC-funded Entrepreneur in an Experimental Market

\begin{tabular}{|c|c|c|c|}
\hline & state 0 & state $(\mathrm{G}, \mathrm{K})$ & state $(U, U)$ or $(B, U)$ \\
\hline $\begin{array}{c}\mathrm{VC} \\
\text { payoff }\end{array}$ & $R_{E M}=\frac{I}{p_{H} \pi_{H} \theta}$ & $R_{G, E M}^{m} \geq \frac{I}{p_{H} \pi_{H}}, \forall m$ & $R_{n, E M}^{\prime} \geq \frac{I}{p_{H} \pi_{H} \theta_{n, E M}^{\prime}}$ \\
\hline $\begin{array}{c}\text { signal } \\
\mathrm{p}_{\mathrm{H}}\end{array}$ & $\begin{array}{l}\text { Continues } \\
\text { project to earn } \\
p_{H}\left(X-R_{E M}\right)\end{array}$ & $\begin{array}{l}\text { Continues project } \\
\quad \text { to earn } \\
p_{H}\left(X-R_{G, E M}^{m}\right)\end{array}$ & Continues project to earn $p_{H}\left(X-R_{n, E M}^{\prime}\right)$. \\
\hline $\begin{array}{c}\text { signal } \\
\mathrm{p}_{\mathrm{M}} \\
\end{array}$ & \multirow{2}{*}{$\begin{array}{c}\text { Stops, and starts } \\
\text { new project to } \\
\text { earn } \\
\pi_{H} p_{H}\left(X-R_{E M}^{\prime}\right)\end{array}$} & \multirow{2}{*}{$\begin{array}{c}\text { Stops, and starts } \\
\text { new project to } \\
\text { earn } \\
p_{H}\left(X-R_{G, E M}^{m+1}\right)\end{array}$} & $\begin{array}{l}\text { Stops, and starts new project to earn } \\
\qquad \pi_{H} p_{H}\left(X-R_{n+1, E M}^{\prime}\right)\end{array}$ \\
\hline $\begin{array}{c}\text { signal } \\
\mathrm{p}_{\mathrm{L}}\end{array}$ & & & $\begin{array}{cc}\text { Stops, and starts } & \text { Stops, and starts new } \\
\text { new project to earn } & \text { project to earn } \\
\pi_{H} p_{H}\left(X-R_{n+1, E M}^{\prime}\right) . & \theta_{n+1, E M}^{\prime} \pi_{H} p_{H}\left(X-R_{n+1, E M}^{\prime}\right) .\end{array}$ \\
\hline
\end{tabular}

Subcase III-A: Experimental Corporate Entrepreneurship

\begin{tabular}{|c|c|c|c|c|}
\hline & state 0 & state $(\mathrm{G}, \mathrm{K})$ & state $(\mathrm{G}, \mathrm{U})$ & state $(\mathrm{U}, \mathrm{U})$ or $(\mathrm{B}, \mathrm{U})$ \\
\hline $\begin{array}{l}\text { Corp. } \\
\text { risk }\end{array}$ & $\frac{I}{R} \leq p_{H} \pi_{H} \theta$ & $\frac{I}{R} \leq p_{H} \pi_{H}$ & $\frac{I}{R} \leq p_{H}$ & $\pi_{H} \theta_{n, E C}, \forall n$ \\
\hline $\begin{array}{l}\text { signal } \\
\mathrm{p}_{\mathrm{H}}\end{array}$ & $\begin{array}{c}\text { Continues } \\
\text { project to earn } \\
p_{H} X-\left(1-p_{H}\right) K\end{array}$ & $\begin{array}{l}\text { Continues project } \\
\text { to earn } \\
p_{H} X-\left(1-p_{H}\right) K_{G, E C}^{m}\end{array}$ & Continues project to & earn $p_{H} X-\left(1-p_{H}\right) K_{n, E C}^{\prime}$. \\
\hline $\begin{array}{c}\text { signal } \\
\mathrm{p}_{\mathrm{M}} \\
\end{array}$ & \multirow{2}{*}{$\begin{array}{l}\text { Stops, and starts } \\
\text { new project to } \\
\text { earn } \\
p_{H} X-\left(1-p_{H}\right) K_{E C}^{\prime}\end{array}$} & \multirow[b]{2}{*}{$\begin{array}{c}\text { Stops, and starts } \\
\text { new project to earn } \\
p_{H} X-\left(1-p_{H}\right) K_{G, E C}^{m+1} \text {. }\end{array}$} & \multicolumn{2}{|c|}{$\begin{array}{l}\text { Stops, and starts new project to earn } \\
\qquad p_{H} X-\left(1-p_{H}\right) K_{n+1, E C}^{\prime}\end{array}$} \\
\hline $\begin{array}{l}\text { signal } \\
\mathrm{p}_{\mathrm{L}}\end{array}$ & & & $\begin{array}{l}\text { Stops, and starts new } \\
\text { project to earn } \\
p_{H} X-\left(1-p_{H}\right) K_{n+1, E C}^{\prime}\end{array}$ & $\begin{array}{c}\begin{array}{c}\text { Stops, and starts new } \\
\text { project if }\end{array} \\
\frac{\theta_{n+1, L C} \pi_{H} p_{H}}{1-\theta_{n+1, L C} \pi_{H} p_{H}}>\frac{K_{n+1, E C}^{\prime}}{X}\end{array}$ \\
\hline
\end{tabular}




\section{Subcase III-B: Conservative Corporate Entrepreneurship}

state 0 state $\mathbf{G}$

$$
\frac{I}{R} \leq\left(p_{H} \pi_{H}+p_{M} \pi_{M}\right) \quad \frac{I}{R} \leq p_{H} \pi_{H} \theta_{n, C C}, \forall n
$$

Continues project to earn Continues project to earn

$$
p_{H} X-\left(1-p_{H}\right) K_{G, C C}^{m} . \quad p_{H} X-\left(1-p_{H}\right) K_{n, C C}^{\prime} .
$$

Continues project to earn Continues project to earn

$$
p_{M} X-\left(1-p_{M}\right) K_{G, C C}^{m} . \quad p_{M} X-\left(1-p_{M}\right) K_{n, C C}^{\prime} .
$$

Stops, and starts new project
if $\begin{gathered}\text { Stops, and starts new } \\ \text { project to earn }\end{gathered}$

Stops, and starts new project
if $\begin{array}{r}\text { Stops, and starts n } \\ \text { project to earn }\end{array}$

Stops, and starts new project if

signal

$\mathrm{p}_{\mathrm{L}} \frac{\theta_{C C}^{\prime}\left(\pi_{H} p_{H}+\pi_{M} p_{M}\right)}{1-\theta_{C C}^{\prime}\left(\pi_{H} p_{H}+\pi_{M} p_{M}\right)}>\frac{K_{C C}^{\prime}}{X} \quad \begin{array}{ll}\left(\pi_{H} p_{H}+\pi_{M} p_{M}\right) X \\ -\left(1-\left(\pi_{H} p_{H}+\pi_{M} p_{M}\right)\right) K_{G, C C}^{m+1}\end{array} \quad \frac{\theta_{n, C C}\left(\pi_{H} p_{H}+\pi_{M} p_{M}\right)}{1-\theta_{n, C C}\left(\pi_{H} p_{H}+\pi_{M} p_{M}\right)}>\frac{K_{n, C C}^{\prime}}{X}$.

\section{Subcase III-C: Ultra-conservative Corporate Entrepreneurship}

\begin{tabular}{cccc}
\hline & state 0 & state G & state S \\
\hline $\begin{array}{c}\text { Corp. } \\
\text { risk }\end{array}$ & $\frac{I}{R} \leq \theta\left(p_{H} \pi_{H}+p_{M} \pi_{M}\right)$ & $\frac{I}{R} \leq\left(p_{H} \pi_{H}+p_{M} \pi_{M}\right)$ & $\frac{I}{R}>\theta_{U C}^{\prime}\left(p_{H} \pi_{H}+p_{M} \pi_{M}\right)$ \\
\hline $\begin{array}{c}\text { signal } \\
\mathrm{p}_{\mathrm{H}}\end{array}$ & $\begin{array}{c}\text { Continues project to } \\
\text { earn } p_{H} X-\left(1-p_{H}\right) K .\end{array}$ & $\begin{array}{c}\text { Continues project to earn } \\
p_{H} X-\left(1-p_{H}\right) K^{\prime} .\end{array}$ & N/A \\
\hline $\begin{array}{c}\text { signal } \\
\mathrm{p}_{M}\end{array}$ & $\begin{array}{c}\text { Continues project to } \\
\text { earn } p_{M} X-\left(1-p_{M}\right) K .\end{array}$ & $\begin{array}{c}\text { Continues project to earn } \\
p_{M} X-\left(1-p_{M}\right) K^{\prime} .\end{array}$ & N/A \\
\hline $\begin{array}{c}\text { signal } \\
\mathrm{p}_{\mathrm{L}}\end{array}$ & Stops. & Stops. & N/A \\
\hline
\end{tabular}


Subcase III-B: Conservative Corporate Entrepreneurship

state 0 state G state U or B

$\frac{I}{R} \leq p_{H} \pi_{H} \theta_{n, C C}, \forall n$

\begin{tabular}{cccc}
$\begin{array}{c}\text { Corp. } \\
\text { risk }\end{array}$ & $\frac{I}{R} \leq \theta\left(p_{H} \pi_{H}+p_{M} \pi_{M}\right)$ & $\frac{I}{R} \leq\left(p_{H} \pi_{H}+p_{M} \pi_{M}\right)$ & $\frac{I}{R} \leq p_{H} \pi_{H} \theta_{n, C C}, \forall n$ \\
\hline $\begin{array}{c}\text { signal } \\
p_{H}\end{array}$ & Continues project to earn & Continues project to earn & Continues project to earn \\
\hline
\end{tabular}

signal Continues project to earn Continues project to earn Continues project to earn

$\mathrm{p}_{\mathrm{M}} \quad p_{M} X-\left(1-p_{M}\right) K . \quad p_{M} X-\left(1-p_{M}\right) K_{G, C C}^{m} . \quad p_{M} X-\left(1-p_{M}\right) K_{n, C C}^{\prime}$.

Stops, and starts new project Stops, and starts new

signal if project to earn

Stops, and starts new project if

$\mathrm{p}_{\mathrm{L}} \frac{\theta_{C C}^{\prime}\left(\pi_{H} p_{H}+\pi_{M} p_{M}\right)}{1-\theta_{C C}^{\prime}\left(\pi_{H} p_{H}+\pi_{M} p_{M}\right)}>\frac{K_{C C}^{\prime}}{X} \quad \begin{array}{ll}\left(\pi_{H} p_{H}+\pi_{M} p_{M}\right) X \\ -\left(1-\left(\pi_{H} p_{H}+\pi_{M} p_{M}\right)\right) K_{G, C C}^{m+1}\end{array} \quad \frac{\theta_{n, C C}\left(\pi_{H} p_{H}+\pi_{M} p_{M}\right)}{1-\theta_{n, C C}\left(\pi_{H} p_{H}+\pi_{M} p_{M}\right)}>\frac{K_{n, C C}^{\prime}}{X}$.

\section{Subcase III-C: Ultra-conservative Corporate Entrepreneurship}

state 0

state $\mathbf{G}$

state $S$

\begin{tabular}{cccc}
\hline $\begin{array}{c}\text { Corp. } \\
\text { risk }\end{array}$ & $\frac{I}{R} \leq \theta\left(p_{H} \pi_{H}+p_{M} \pi_{M}\right)$ & $\frac{I}{R} \leq\left(p_{H} \pi_{H}+p_{M} \pi_{M}\right)$ & $\frac{I}{R}>\theta_{U C}^{\prime}\left(p_{H} \pi_{H}+p_{M} \pi_{M}\right)$ \\
\hline $\begin{array}{c}\text { signal } \\
\mathrm{p}_{\mathrm{H}}\end{array}$ & $\begin{array}{c}\text { Continues project to } \\
\text { earn } p_{H} X-\left(1-p_{H}\right) K .\end{array}$ & $\begin{array}{c}\text { Continues project to earn } \\
p_{H} X-\left(1-p_{H}\right) K^{\prime} .\end{array}$ & N/A \\
\hline $\begin{array}{c}\text { signal } \\
\mathrm{p}_{\mathrm{M}}\end{array}$ & $\begin{array}{c}\text { Continues project to } \\
\text { earn } p_{M} X-\left(1-p_{M}\right) K .\end{array}$ & $\begin{array}{c}\text { Continues project to earn } \\
p_{M} X-\left(1-p_{M}\right) K^{\prime} .\end{array}$ & N/A \\
\hline $\begin{array}{c}\text { signal } \\
\mathrm{p}_{\mathrm{L}}\end{array}$ & Stops. & Stops. & N/A \\
\hline
\end{tabular}

